\title{
BMJ Open Associations between diabetes duration and self-stigma development in Japanese people with type 2 diabetes: a secondary analysis of cross- sectional data
}

\author{
Asuka Kato (1) , ${ }^{1}$ Yuko Fujimaki, ${ }^{2}$ Shin Fujimori, ${ }^{2}$ Akihiro Isogawa, ${ }^{3}$ Yukiko Onishi, ${ }^{4}$ \\ Ryo Suzuki, ${ }^{5,6}$ Kohjiro Ueki, ${ }^{5,7}$ Toshimasa Yamauchi, ${ }^{5}$ Takashi Kadowaki, ${ }^{5,8}$ \\ Hideki Hashimoto ${ }^{1}$
}

To cite: Kato A, Fujimaki Y, Fujimori S, et al. Associations between diabetes duration and self-stigma development in Japanese people with type 2 diabetes: a secondary analysis of crosssectional data. BMJ Open 2021;11:e055013. doi:10.1136/ bmjopen-2021-055013

- Prepublication history for this paper is available online. To view these files, please visit the journal online (http://dx.doi. org/10.1136/bmjopen-2021055013).

Received 29 June 2021 Accepted 29 November 2021

Check for updates

(C) Author(s) (or their employer(s)) 2021. Re-use permitted under CC BY-NC. No commercial re-use. See rights and permissions. Published by BMJ.

For numbered affiliations see end of article.

Correspondence to

Dr Asuka Kato;

asukakato-tky@umin.ac.jp

\section{ABSTRACT}

Objectives To examine the associations between selfstigma and diabetes duration in a sample of Japanese people with type 2 diabetes.

Design A secondary analysis of a cross-sectional study. Setting Two university hospitals, one general hospital and one clinic in Tokyo, Japan.

Participants Outpatients with type 2 diabetes aged 2074 years and receiving treatment from diabetes specialist physicians $(n=209)$ completed a self-administered questionnaire.

Primary and secondary outcome measures Self-stigma was measured as the primary outcome. Patient Activation Measure, body mass index and haemoglobin A1c were measured as secondary outcomes.

Results One-way analysis of covariance showed significant differences in self-stigma levels between the five groups of diabetes duration ( $\leq 5$ years, $6-10$ years, $11-15$ years, $16-21$ years and 22 years or more) after controlling for age, gender, education, marital status, diabetes treatment (insulin use) and diabetesrelated complications, $F(4,198)=2.83, p=0.026$. Multiple comparisons using Bonferroni correction showed statistically significant differences in self-stigma levels between the groups with $\leq 5$ years $(95 \% \mathrm{Cl} 59.63$ to 69.73 ) and $11-15$ years with diabetes $(95 \% \mathrm{Cl} 71.12$ to 80.82 ; $p=0.020$ ). The highest mean level of self-stigma was observed in the group having diabetes for 11-15 years. Conclusions Self-stigma was associated with diabetes duration and was lowest after diagnosis and gradually increased, with its highest levels being observed in those having diabetes for 11-15 years. Self-stigma takes time to develop and gradually increases in individuals as it is learnt through direct experiences of diabetes-related stigma after self-administering treatment in everyday social situations.

\section{INTRODUCTION}

In recent years, researchers worldwide have shown interest in diabetes-related stigma, with a number of studies focusing on this topic. ${ }^{1-5}$
Strengths and limitations of this study

- This study is the first to examine the associations between self-stigma and diabetes duration using a secondary analysis of cross-sectional data.

- This study's strength includes its analysis of selfstigma development in a sample of outpatients with type 2 diabetes mellitus (T2DM) with varying lengths of time since diagnosis.

- The duration of living with T2DM was classified into five groups by diabetes duration quintiles: (1) $\leq 5$ years, (2) 6-10 years, (3) 11-15 years, (4) 16-21 years and (5) $\geq 22$ years to capture at different stages of disease management.

- Our findings have generalisability as the study sample reflected varying types of patients from four different types of medical facilities (two university hospitals, a general hospital and a clinic).

- Owing to the limitations of this study's crosssectional design, causal inferences regarding the relationships between self-stigma and diabetes duration cannot be made.

Goffman published his pioneering study in 1963 on the concept of stigma, and since then, it has been redefined and reworked by sociologists and social psychologists. ${ }^{6-12}$ Stigma has been generally defined as any attribute likely to put an individual at odds with societal norms, resulting in negative stereotyping, prejudice, blame, rejection, status loss and discrimination. ${ }^{6-12}$ It is known that the onset of type 2 diabetes mellitus (T2DM) and the progression of its complications are interconnected with both environmental and genetic factors. ${ }^{13} 14$ Nevertheless, T2DM is conventionally evaluated using an external perspective (eg, diet, exercise) rather than an intrinsic genetic-based method. ${ }^{1315}$ 
From a stigmatised person's viewpoint, stigma can be understood as taking three forms. ${ }^{16-20}$ First, experienced stigma refers to a person experiencing discrimination due to social unacceptability. ${ }^{16}{ }^{19}$ Second, perceived stigma occurs when a person fears shameful, discriminatory situations and/or detrimental treatment because of their condition. ${ }^{16}{ }^{19}$ Third, self-stigma is when people are aware of negative stereotypes, prejudices, and discrimination regarding themselves, agree with them, and direct these negative and biased beliefs, feelings and behaviours internally. ${ }^{171820}$

Perceived stigma occurs in individuals with T2DM before their diagnosis and affects a wide range of individuals' health behaviours. ${ }^{121-26}$ For example, avoiding screening tests, refusing a diabetes diagnosis, delaying treatment and concealing a diagnosis from family members are forms of perceived stigma. ${ }^{121-26}$ In contrast, selfstigma occurs in individuals with T2DM during disease management. Empirical research has demonstrated that increased self-stigma negatively impacts the quality of patients' interactions with healthcare professionals and their self-management behaviours, ${ }^{27}$ specifically patients' activation to engage in self-care, which it affects directly and indirectly through self-esteem and self-efficacy. 2829 Activating patients to engage in self-care is critical for increasing patients' ability to gain the knowledge, skills, confidence, and behaviours required to manage their illness. $^{30} 31$ A recent prospective longitudinal study reported that patients' activation is associated with their diet and exercise behaviours as well as a reduction in body mass index (BMI), weight and glycated haemoglobin (HbA1c) among people with T2DM. ${ }^{32}$ Given these evidences, we elected to include patients' activation to engage in self-care, BMI and HbA1c as secondary outcome variables in this study.

Limited research has examined when self-stigma develops during the disease management process. Many studies on diabetes-related stigma have overlooked the differences between self-stigma and perceived stigma, especially the components distinctive to self-stigma resulting in patients internally directing their negative attitudes and behaviours. ${ }^{27} 3334$ People with T2DM are unlikely to begin applying negative attitudes and behaviours internally immediately after diagnosis. Based on the existing research, we hypothesised that self-stigma needs time to develop, such that its level is the lowest at the time of diagnosis and the early stages of treatment. Therefore, this study aimed to examine the associations between self-stigma and diabetes duration in people with T2DM using secondary data analysis of our previous crosssectional study. ${ }^{2}$

\section{METHODS}

\section{Participants}

We conducted a secondary analysis using cross-sectional data from a self-administered questionnaire for outpatients with T2DM receiving treatment from diabetes specialist physicians at hospitals in Tokyo, Japan. The eligibility criteria for the participants included (1) being diagnosed with T2DM, (2) being aged 20-74 years, (3) speaking Japanese as a native language, (4) having no problem with cognitive functions and (5) requiring no urgent medical procedures on the day of completion of the questionnaire at the physicians' discretion.

A detailed description of the study procedures has been published previously. ${ }^{2}$ After a clinic visit, physicians used a consecutive sampling method, and distributed a letter explaining the survey questionnaire to their eligible patients after screening for the inclusion criteria based on patients' medical records. Thus, except for the patients having an exclusion criterion, including cognitive impairment, physicians distributed the letter to all their patients on the corresponding day of recruitment. The research staff spoke to the patients who received the letter in a separate, private room at the hospital and explained the purpose of the study to patients who met the eligibility criteria. Only patients who provided written informed consent participated. The research staff distributed the questionnaire to participants and asked them to answer it individually.

As for the sample size, this study was a secondary data analysis of our previous study ${ }^{2}$; thus, a post hoc power analysis was conducted using $\mathrm{G}^{*}$ Power (V.3.1) to calculate the actual power $(\beta=0.25)$ and effect size $(0.23)$ on the basis of a one-way analysis of covariance (ANCOVA), a two-tailed $\alpha=0.05$, a final sample size of 209 and six covariates.

\section{Measures}

The following items were investigated using a selfadministered anonymous questionnaire: age, gender, height, weight, diabetes duration (years), education (years), marital status, diabetes treatment (eg, oral hypoglycaemic agents, insulin injection and other injection therapy) and their HbAlc level on the day they completed the questionnaire, which was written down directly from the blood test result. BMI was calculated using patients' height and weight. Both BMI and HbAlc were used as secondary outcomes to understand the clinical characteristics by their diabetes duration. Diabetes-related complications were calculated by the research staff based on patient-report with reference to the Diabetes Complications Index. ${ }^{35}$ Participants took approximately $15-20 \mathrm{~min}$ to complete the whole questionnaire. Additionally, the questionnaire included scales measuring self-stigma and patient activation.

\section{Self-stigma}

Self-stigma was measured as the primary outcome. To assess self-stigma levels, we used a reliable and validated instrument-the Japanese version of the Self-Stigma Scale (SSS-J). ${ }^{18} 20$ The scale consists of 39 items evaluated on a 4-point Likert scale ranging from strongly disagree to strongly agree (rated from 0 to 4 ), with total scores ranging from 0 to 117 points as a continuous variable. Higher 


\begin{tabular}{|c|c|c|}
\hline Participant characteristics & $\mathbf{n}$ or $\mathbf{M}$ & $\begin{array}{l}\% \text { or } \\
\text { SD }\end{array}$ \\
\hline \multicolumn{3}{|l|}{ Gender } \\
\hline Men & 168 & 80.4 \\
\hline Women & 41 & 19.6 \\
\hline Age (years) & 60.2 & 10.1 \\
\hline BMI $\left(\mathrm{kg} / \mathrm{m}^{2}\right)$ & 26.3 & 5.2 \\
\hline Duration of diabetes (years) & 13.3 & 9.4 \\
\hline \multicolumn{3}{|l|}{ Primary treatment } \\
\hline Oral hypoglycaemic agents & 123 & 58.9 \\
\hline Insulin injections & 15 & 7.2 \\
\hline $\begin{array}{l}\text { Insulin injections and oral hypoglycaemic } \\
\text { agents }\end{array}$ & 44 & 21.1 \\
\hline $\begin{array}{l}\text { Other injectable medications (other than } \\
\text { insulin) }\end{array}$ & 14 & 6.7 \\
\hline Lifestyle & 13 & 6.2 \\
\hline Diabetes-related complications $(0-6)^{*}$ & 0.57 & 0.86 \\
\hline HbA1c (\%) & 7.3 & 1.2 \\
\hline $\mathrm{HbA1c}(\mathrm{mmol} / \mathrm{mol})$ & 56 & 13.1 \\
\hline Education (years) & 13.9 & 2.3 \\
\hline \multicolumn{3}{|l|}{ Marital status } \\
\hline Married & 151 & 72.2 \\
\hline Unmarried/divorced/bereaved & 58 & 27.8 \\
\hline
\end{tabular}

*The Diabetes Complications Index.

$\mathrm{BMI}$, body mass index; HbA1c, glycated haemoglobin; M, mean.

total scores indicated higher self-stigma levels. The internal consistency of the SSS-J in this study was 0.96 . Sample items of the scale were as follows: 'Being a patient with diabetes takes away many opportunities from me', 'I have negative feelings about myself with diabetes' and 'I avoid interacting with others because I am a patient with diabetes'.

\section{Patient activation}

The Japanese version of the Patient Activation Measure (PAM-13) was used as a secondary outcome to understand clinical characteristics by diabetes duration. The scale is a reliable and validated instrument that can assess patients' activation levels for engaging in self-care. ${ }^{36}$ The PAM-13 can comprehensively measure the patients' activation levels for self-care, such as the patients' knowledge, skills, confidence and behaviours required to manage their illness. ${ }^{30}{ }^{31}$ Previous studies showed that the scale could predict not only dietary and exercise behaviours but also comprehensive behaviours that include diseasespecific self-management behaviours (eg, glucose monitoring, taking medications). ${ }^{30}{ }^{37}$ We intentionally selected the PAM-13 because it considers both single instances of self-care behaviours and a person's knowledge, skills and beliefs regarding their chronic disease management. The scale consists of 13 items evaluated on a 4-point
Likert scale ranging from strongly disagree to strongly agree. Total scores ranged from 13 to 52, and the scores were converted to an interval scale score (0 to 100) based on the algorithm by the scale developer. ${ }^{30}$ The higher the total score, the higher the patients' activation level for self-care. The internal consistency of the PAM-13 in this study was 0.85 . Sample items of the scale were as follows: 'I am confident that I can follow through on medical treatments I may need to do at home' and 'I have been able to maintain (keep up with) lifestyle changes, like eating right or exercising'.

\section{Statistical analyses}

This study was a secondary analysis of cross-sectional data collected in our previous study. ${ }^{2}$ The dataset was generated by AK, YF, SF, AI, YO, RS, KU, TY, TK and HH, and some of the data are openly available in Dryad. ${ }^{38}$ For descriptive statistics, we calculated continuous data using means and SD and categorical data using frequencies and percentages. Participants were classified into the following five groups by diabetes duration quintiles: $(1) \leq 5$ years, (2) 6-10 years, (3) 11-15 years, (4) 16-21 years and (5) $\geq 22$ years. Next, we calculated the mean and $95 \%$ CI for self-stigma, PAM-13, BMI and HbAlc of each group. We compared each diabetes duration group for differences in their levels of self-stigma, PAM-13, BMI and HbAlc, using ANCOVAs after controlling for age, gender, education, marital status, diabetes treatment (insulin use) and diabetes-related complications as possible confounders based on our previous study. ${ }^{2}$ When significant main effects were found, we conducted multiple comparison tests with Bonferroni corrections. The significance level was set at $p<0.05$. We used SPSS V.23.0 (SPSS Japan) to conduct all analyses.

\section{Patient and public involvement}

No patients were involved in designing this study, recruiting participants or conducting the study. However, they were informed that the research team would disseminate the final study findings to them and the public.

\section{RESULTS}

We asked 259 outpatients with T2DM to participate in the study at four medical facilities (two university hospitals, one general hospital and one clinic) in Tokyo, Japan and obtained written informed consent forms from 218 (participation rate $84.2 \%$ ). Of these, 217 completed the questionnaire (one declined). We excluded five participants who chose strongly disagree for all 39 items of SSS-J from the analysis because it was uncertain whether the scale was able to measure what it was originally intended to assess. We also excluded three participants who chose strongly agree for all 13 items of the PAM-13 from the analysis as per the instructions from the scale developer. ${ }^{30}$ Therefore, the final analytic sample included 209 participants. There were no missing data both in the scales and participants' demographics. 
Table 2 Means, 95\% Cls and one-way analyses of covariance of self-stigma levels, PAM-13 scores, BMI and HbA1c levels of the five different groups of diabetes duration

\begin{tabular}{|c|c|c|c|c|c|c|c|c|}
\hline \multirow[b]{2}{*}{ Measure } & \multirow[b]{2}{*}{ Group } & \multirow[b]{2}{*}{$\mathbf{n}$} & \multirow[b]{2}{*}{$\mathbf{M}$} & \multicolumn{2}{|c|}{$95 \% \mathrm{Cl}$} & \multirow[b]{2}{*}{$\mathbf{F}$} & \multirow[b]{2}{*}{$P$ value } & \multirow[b]{2}{*}{ Partial $\eta^{2}$} \\
\hline & & & & LL & UL & & & \\
\hline \multirow[t]{3}{*}{ Self-stigma* } & $\leq 5$ years & 44 & 64.68 & 59.63 & 69.73 & 2.83 & 0.026 & 0.05 \\
\hline & $11-15$ years & 42 & 75.97 & 71.12 & 80.82 & & & \\
\hline & 16-21 years & 32 & 74.62 & 69.03 & 80.22 & & & \\
\hline \multirow[t]{4}{*}{ PAM-13† } & $\leq 5$ years & 44 & 53.50 & 50.58 & 56.42 & 0.48 & 0.748 & 0.01 \\
\hline & $6-10$ years & 50 & 50.94 & 48.33 & 53.55 & & & \\
\hline & $11-15$ years & 42 & 51.67 & 48.86 & 54.47 & & & \\
\hline & 16ᄀ21 years & 32 & 51.96 & 48.73 & 55.20 & & & \\
\hline \multirow{3}{*}{ BMI $\left(\mathrm{kg} / \mathrm{m}^{2}\right)$} & $11-15$ years & 42 & 25.41 & 24.01 & 26.80 & & & \\
\hline & 16-21 years & 32 & 25.95 & 24.35 & 27.56 & & & \\
\hline & $\geq 22$ years & 41 & 25.76 & 24.25 & 27.27 & & & \\
\hline \multirow[t]{5}{*}{$\mathrm{HbA1c}(\%)$} & $\leq 5$ years & 44 & 7.41 & 7.08 & 7.73 & 0.36 & 0.837 & 0.01 \\
\hline & $6-10$ years & 50 & 7.22 & 6.93 & 7.51 & & & \\
\hline & $11-15$ years & 42 & 7.32 & 7.00 & 7.63 & & & \\
\hline & 16-21 years & 32 & 7.28 & 6.91 & 7.64 & & & \\
\hline & $\geq 22$ years & 41 & 7.14 & 6.80 & 7.48 & & & \\
\hline
\end{tabular}

Means were calculated after controlling for age, gender education, marital status, diabetes treatment (insulin use) and diabetes-related complications.

${ }^{*}$ The Japanese version of Self-Stigma Scale (SSS-J).

†Patient Activation Measure.

BMI, body mass index; HbA1c, glycated haemoglobin; M, mean; PAM-13, Patient Activation Measure.

Table 1 shows participants' sociodemographic and clinical characteristics. The mean age of the participants was 60.2 years $(\mathrm{SD}=10.1$, range $23-74)$, and the proportion of men was $80.4 \% \quad(n=168)$. The mean duration of diabetes was 13.3 years $(\mathrm{SD}=9.4$, range $0.1-51.0)$ and the mean score on the Diabetes Complications Index was 0.57 ( $\mathrm{SD}=0.86$, range $0-4$ ). About $60 \%$ of participants used hypoglycaemic agents without insulin and other injections. Participants reported having a mean education of 13.9 years $(\mathrm{SD}=2.3$, range $9-18)$, and about $70 \%$ of the participants were married.

Table 2 shows the results of ANCOVAs for differences in self-stigma, PAM-13, BMI and HbA1c by diabetes duration. Figure 1 shows the mean self-stigma levels by diabetes duration group. The ANCOVA showed a significant difference in self-stigma levels between the five groups after controlling for age, gender, education, marital status, diabetes treatment (insulin use) and diabetes-related complications, $\mathrm{F}(4,198)=2.83, \mathrm{p}=0.026$. The lowest mean self-stigma level was observed in the diabetes group with $\leq 5$ years and increased in order from 6-10 years to $11-15$ years of diabetes. The highest mean self-stigma level was observed in the group with 11-15 years of diabetes and decreased in order from 16-21 years to 22 years or more. Multiple comparisons using

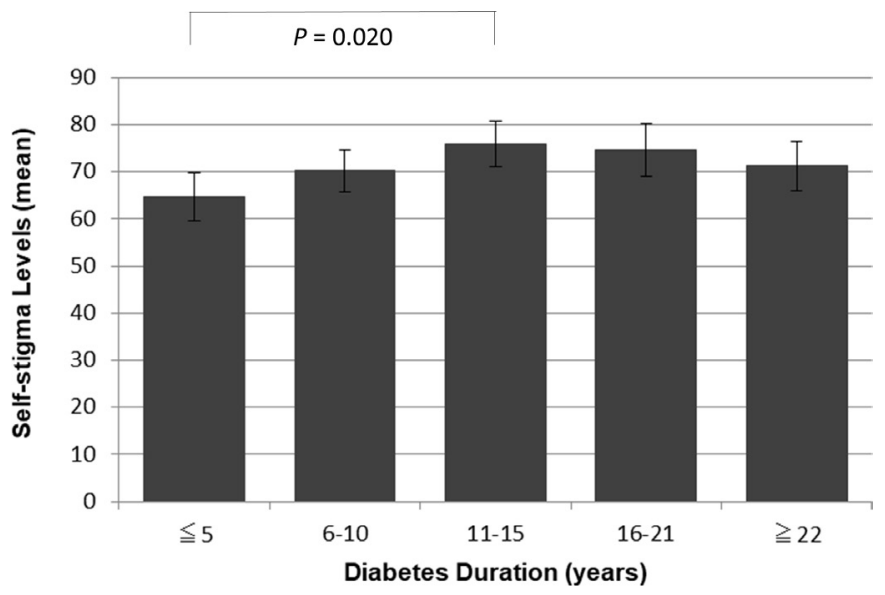

Figure 1 Mean self-stigma levels (SSS-J) of diabetes duration ( $n=209)$ groups. Self-stigma, The Japanese version of Self-Stigma Scale (SSS-J). 

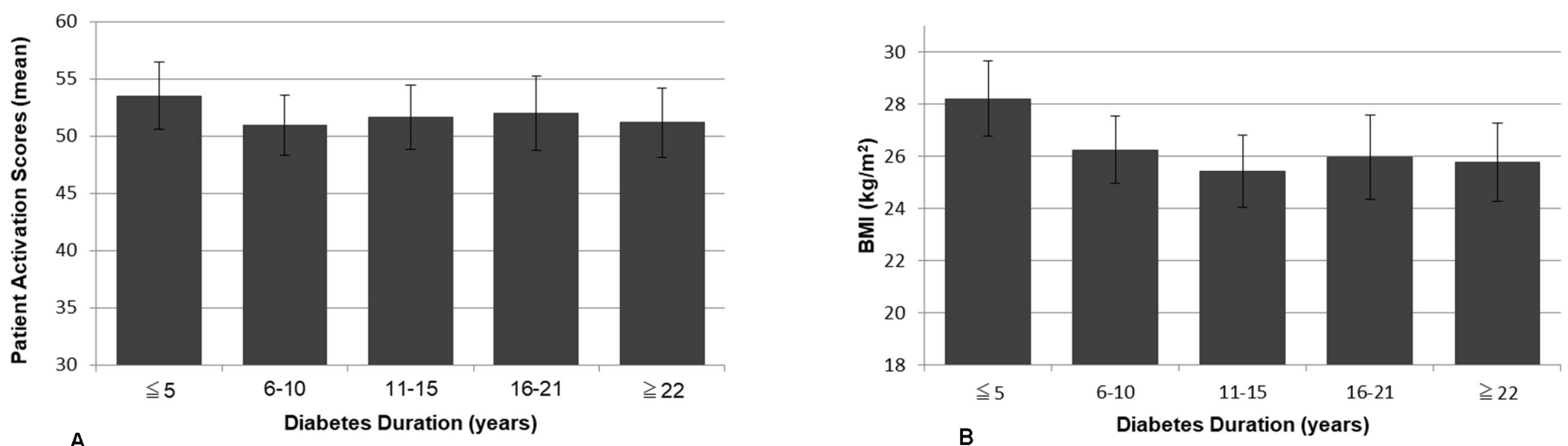

Figure 2 (A) Mean patient activation scores (PAM-13) of diabetes duration ( $n=209)$ groups. (B) Mean BMI of diabetes duration $(n=209)$ groups. Patient Activation, Patient Activation Measure (PAM-13). BMI, body mass index.

Bonferroni correction showed that there were statistically significant differences in self-stigma levels between the groups with $\leq 5$ years (95\% CI 59.63 to 69.73 ) and $11-15$ years of diabetes (95\% CI 71.12 to $80.82, \mathrm{p}=0.020$ ).

Figure 2 shows the mean PAM-13 and BMI by diabetes duration group. The highest mean PAM-13 level was observed in the group with $\leq 5$ years of diabetes. There was a tendency for maintaining consistent levels for the rest of the four groups according to diabetes duration, though there were no significant differences in mean PAM-13 levels, $\mathrm{F}(4,198)=0.48, \mathrm{p}=0.748$. The lowest mean BMI level was observed in the group with 11-15 years of diabetes, though there were no significant differences in mean BMI levels, $F(4,198)=2.07, p=0.086$. As for mean HbA1c levels, there were no significant group differences, $\mathrm{F}(4,198)=0.35, \mathrm{p}=0.837$.

\section{DISCUSSION}

This study examined self-stigma development by diabetes duration using a secondary analysis of cross-sectional data among Japanese people with T2DM. The study's main finding was identifying an association between self-stigma and diabetes duration, with self-stigma being the lowest immediately after diagnosis and gradually increasing to its highest levels in those with a diabetes duration of 11-15 years.

The current findings are consistent with the existing literature on T2DM. ${ }^{39} 40$ For example, our findings were consistent with research demonstrating an association between age and diabetes stigma ${ }^{4}$ that found that younger patients, who are typically socially active, were at an increased risk of experiencing socially unjustified and unequal treatment because of their condition compared with older patients. ${ }^{4}$ Similarly, our study found that self-stigma was less likely to occur immediately following a participant's diagnosis but rather developed gradually after receiving treatment and directly experiencing diabetes-related stigma in everyday social life. Moreover, our findings support those by Scheff, who argued that negative stereotypes toward illness are learnt and reinforced in daily life through socialisation and can ultimately change one's self-perception and social opportunities. ${ }^{39}$

Interestingly, while self-stigma was highest in the group with a diabetes duration of 11-15 years, self-stigma was shown to decrease gradually for those who had diabetes for 16-21 years and $\geq 22$ years. One potential explanation for this gradual decrease is that self-stigma may decrease in patients as they socially adapt to their illness on their own. The age range of the study participants was widely distributed for each group based on diabetes duration (eg, 11-15 years of diabetes: 43-72 years old, 16-21 years of diabetes: 47-74 years old, 22 or more years of diabetes: 52-73 years old). There were six fully retired participants in the group with 11-15 years of diabetes, five in the group with 16-21 years of diabetes and two in the group with 22 years or more of diabetes. Thus, the gradual decrease in self-stigma in the group with 16 or more years of diabetes, was considered more likely the result of illness adaption, rather than effects of older age and/or retirement. This explanation is supported by our previous qualitative research showing that some patients independently adapt to their illness as they discover positive self-representations through diabetes treatment (eg, realising that one does not lack self-control) over time. ${ }^{40}$ Our previous study also showed that people with T2DM took approximately $10-15$ years to discover positive self-representations. ${ }^{40}$

It is important to note that perceived stigma does not necessarily require patients' direct experiences and can even occur before diagnosis via surrogate experiences (eg, other patients, family members, colleagues and friends). ${ }^{21} 2226$ Thus, unlike perceived stigma, this study showed that self-stigma has distinct characteristics in the context of its time of occurrence and the learning pathways since self-stigma cannot be developed secondhand but requires direct experiences. To our best knowledge, this represents the first study to analyse the associations between self-stigma and diabetes duration, and its strength and contributions are in its unique analysis of the development of self-stigma using a sample of people 
with T2DM who had lived with a diabetes diagnosis for a long time.

This study had several limitations. First, this study used a cross-sectional design as a part of the secondary analysis of an existing dataset; thus, causal inferences regarding the relationships between self-stigma and diabetes duration cannot be made. Future research should collect prospective longitudinal data to verify the relationships between self-stigma, diabetes duration, and patients' activation to engage in self-care. Second, the study participants were currently being seen and treated by diabetes specialist physicians; thus, participants receiving medical treatment from general practitioners were not included. Therefore, the study results may not be generalised to the entire T2DM population with varying severity levels in Japan. Further studies will be needed in the future for collecting data from people with different T2DM severities who are treated by both specialists and general practitioners.

\section{Conclusions}

Despite these limitations, this secondary data analysis identified several distinctive characteristics of self-stigma and contributed to the literature on diabetes self-stigma. Further, the results have important practical implications for clinical practice. Self-stigma was found to develop approximately 10-15 years after diagnosis in individuals with T2DM; thus, self-stigma could be attenuated or prevented using an appropriately timed intervention before patients are at risk of self-stigma. Healthcare professionals can provide some consultation with psychosocial care (eg, psychosocial referrals for patients needing additional support), particularly for patients whose diabetes duration is $10-15$ years and who have yet to display proactive self-engagement for their diabetes treatment. Generally, after patients live with diabetes for many years (eg, more than 10 years), physicians expect patients to better understand diabetes and its treatment and to have adapted to their illness. Accordingly, these patients' selfengagement for diabetes treatment has been expected to become increasingly internally motivated and proactive over time. However, in this study, people with T2DM that had a duration of 11-15 years displayed some clinical characteristics that differed from other groups, including lower patient activation levels for self-care and the lowest BMI levels, although these differences were not statistically significant between the groups. Therefore, healthcare professionals should remember that self-stigma can have long-term effects on patients' activation for engaging in self-care that can affect them throughout their lifetime of treatment.

\section{Author affiliations}

${ }^{1}$ Department of Health and Social Behavior, School of Public Health, The University of Tokyo, Tokyo, Japan

${ }^{2}$ Department of Internal Medicine, School of Medicine, Teikyo University, Tokyo, Japan

${ }^{3}$ Diabetes Care Division, Mitsui Memorial Hospital, Tokyo, Japan

${ }^{4}$ Division of Diabetes and Metabolism, The Institute of Medical Science, Asahi Life Foundation, Tokyo, Japan
${ }^{5}$ Department of Diabetes and Metabolic Diseases, Graduate School of Medicine, The University of Tokyo, Tokyo, Japan

${ }^{6}$ Department of Diabetes, Endocrinology and Metabolism, Tokyo Medical University, Tokyo, Japan

${ }^{7}$ Diabetes Research Center, National Center for Global Health and Medicine Research Institute, Tokyo, Japan

${ }^{8}$ Toranomon Hospital, Tokyo, Japan

Acknowledgements We are grateful to the physicians who recruited patients for this study, the many graduate students who helped with data collection and particularly all study participants.

Contributors AK conceptualised and designed the study. AK coordinated the study acquired, analysed, and interpreted the data, and prepared the paper. HH and TK helped to analyse and interpret the data. AK and $\mathrm{HH}$ held primary responsibility for data access. YF, SF, Al, YO, RS, KU, TY and TK made significant contributions to the critical interpretation of the results in terms of important practical content. All authors read and approved the final version of the manuscript. HH and AK accept full responsibility for the work. HH, TK, SF, Al and YO accept full responsibility for the conduct of the study. AK and $\mathrm{HH}$ had primary responsibility for the data access. All authors controlled the decision to publish.

Funding The authors have not declared a specific grant for this research from any funding agency in the public, commercial or not-for-profit sectors.

Competing interests None declared.

Patient and public involvement Patients and/or the public were not involved in the design, or conduct, or reporting, or dissemination plans of this research.

Patient consent for publication Not applicable.

Ethics approval This study involves human participants and this survey was conducted with prior approval by the Research Ethics Committee of the University of Tokyo Graduate School of Medicine and Faculty of Medicine and each participating medical facility. The secondary analysis conducted in this study was exempt from another IRB approval (Approval No. 3269; 17 September 2013). Participants gave informed consent to participate in the study before taking part.

Provenance and peer review Not commissioned; externally peer reviewed.

Data availability statement Data are available in a public, open access repository. Data are available upon reasonable request. The data that support the findings of this study are available from the corresponding author upon reasonable request. Also, some data presented in this study are openly available in Dryad at https://doi. org/10.5061/dryad.dncjsxkwd.

Open access This is an open access article distributed in accordance with the Creative Commons Attribution Non Commercial (CC BY-NC 4.0) license, which permits others to distribute, remix, adapt, build upon this work non-commercially, and license their derivative works on different terms, provided the original work is properly cited, appropriate credit is given, any changes made indicated, and the use is non-commercial. See: http://creativecommons.org/licenses/by-nc/4.0/.

ORCID iD

Asuka Kato http://orcid.org/0000-0002-4578-3630

\section{REFERENCES}

1 Browne JL, Ventura A, Mosely K, et al. 'I call it the blame and shame disease': a qualitative study about perceptions of social stigma surrounding type 2 diabetes. BMJ Open 2013;3:e003384.

2 Kato A, Fujimaki Y, Fujimori S, et al. Association between self-stigma and self-care behaviors in patients with type 2 diabetes: a crosssectional study. BMJ Open Diabetes Res Care 2016;4:e000156.

3 Liu NF, Brown AS, Folias AE, et al. Stigma in people with type 1 or type 2 diabetes. Clin Diabetes 2017;35:27-34.

4 Gredig D, Bartelsen-Raemy A. Diabetes-related stigma affects the quality of life of people living with diabetes mellitus in Switzerland: implications for healthcare providers. Health Soc Care Community 2017;25:1620-33.

5 Olesen K, Cleal B, Willaing I. Discrimination and stigma among people with type 2 diabetes in the workplace: prejudice against illness or obesity? Public Health 2020;180:100-1.

6 Goffman E. Stigma: notes on the management of spoiled identity New York: Prentice-Hall, 1963.

7 Jones EE, Farina A, Hastorf AH. Social stigma: the psychology of marked relationships. New York: Freeman, 1984. 
8 Crocker J, Major B, Steele C. Social stigma. In: Fiske S, Gilbert D, Lindzey G, eds. Handbook of social psychology. Boston: McGrawHill, 1998: 504-53.

9 Major B, O'Brien LT. The social psychology of stigma. Annu Rev Psychol 2005;56:393-421.

10 Link BG, Phelan JC. Conceptualizing stigma. Annu Rev Sociol 2001;27:363-85.

11 Ottati V, Bodenhausen GV, Newman LS. Social psychological models of mental illness stigma. In: Corrigan PW, ed. On the stigma of mental illness: practical strategies for research and social change. Washington, DC: APA, 2005: 99-128.

12 Corrigan PW, Watson AC. The paradox of self-stigma and mental illness. Clin Psychol Sci Pract 2002;9:35-53.

13 Wilmot E, Idris I. Early onset type 2 diabetes: risk factors, clinical impact and management. Ther Adv Chronic Dis 2014;5:234-44.

14 Zarkesh M, Daneshpour MS, Faam B, et al. Heritability of the metabolic syndrome and its components in the Tehran lipid and glucose study (TLGS). Genet Res 2012;94:331-7.

15 Kato A, Fujimaki Y, Fujimori S, et al. A qualitative study on the impact of internalized stigma on type 2 diabetes self-management. Patient Educ Couns 2016;99:1233-9.

16 Jacoby A. Felt versus enacted stigma: a concept revisited: evidence from a study of people with epilepsy in remission. Soc Sci Med 1994;38:269-74

17 Corrigan PW, Wassel A. Understanding and influencing the stigma of mental illness. J Psychosoc Nurs Ment Health Serv 2008;46:42-8.

18 Mak WWS, Cheung RYM. Self-stigma among concealable minorities in Hong Kong: conceptualization and unified measurement. Am J Orthopsychiatry 2010;80:267-81.

19 Browne JL, Ventura AD, Mosely K, et al. Measuring the stigma surrounding type 2 diabetes: development and validation of the type 2 diabetes stigma assessment scale (DSAS-2). Diabetes Care 2016;39:2141-8.

20 Kato A, Takada M, Hashimoto $\mathrm{H}$. Reliability and validity of the Japanese version of the self-stigma scale in patients with type 2 diabetes. Health Qual Life Outcomes 2014;12:179.

21 Hallgren EA, McElfish PA, Rubon-Chutaro J. Barriers and opportunities: a community-based participatory research study of health beliefs related to diabetes in a US Marshallese community. Diabetes Educ 2015;41:86-94.

22 Weiler DM, Crist JD. Diabetes self-management in a Latino social environment. Diabetes Educ 2009;35:285-92.

23 Finucane ML, McMullen CK. Making diabetes self-management education culturally relevant for Filipino Americans in Hawaii. Diabetes Educ 2008;34:841-53.

24 Nam S, Song H-J, Park S-Y, et al. Challenges of diabetes management in immigrant Korean Americans. Diabetes Educ 2013:39:213-21.

25 Willig AL, Richardson BS, Agne A, et al. Intuitive eating practices among African-American women living with type 2 diabetes: a qualitative study.

$J$ Acad Nutr Diet 2014;114:889-96.
26 Winkley K, Evwierhoma C, Amiel SA, et al. Patient explanations for non-attendance at structured diabetes education sessions for newly diagnosed type 2 diabetes: a qualitative study. Diabet Med 2015;32:120-8.

27 Puhl RM, Himmelstein MS, Hateley-Browne JL, et al. Weight stigma and diabetes stigma in U.S. adults with type 2 diabetes: associations with diabetes self-care behaviors and perceptions of health care. Diabetes Res Clin Pract 2020;168:108387.

28 Kato A, Fujimaki Y, Fujimori S, et al. Psychological and behavioural patterns of stigma among patients with type 2 diabetes: a crosssectional study. BMJ Open 2017;7:e013425.

29 Kato A, Fujimaki Y, Fujimori S, et al. How self-stigma affects patient activation in persons with type 2 diabetes: a cross-sectional study. BMJ Open 2020;10:e034757.

30 Hibbard JH, Mahoney ER, Stockard J, et al. Development and testing of a short form of the patient activation measure. Health Serv Res 2005;40:1918-30.

31 Hibbard JH, Stockard J, Mahoney ER, et al. Development of the patient activation measure (PAM): conceptualizing and measuring activation in patients and consumers. Health Serv Res 2004;39:1005-26.

32 Regeer H, van Empelen P, Bilo HJG, et al. Change is possible: how increased patient activation is associated with favorable changes in well-being, self-management and health outcomes among people with type 2 diabetes mellitus: a prospective longitudinal study. Patient Educ Couns 2021;43.

33 Holmes-Truscott E, Ventura AD, Thuraisingam S, et al. Psychosocial moderators of the impact of diabetes stigma: results from the second diabetes MILES - Australia (MILES-2) Study. Diabetes Care 2020;43:2651-9.

34 Himmelstein MS, Puhl RM. At multiple fronts: diabetes stigma and weight stigma in adults with type 2 diabetes. Diabet Med 2021;38:e14387.

35 Fincke BG, Clark JA, Linzer M, et al. Assessment of long-term complications due to type 2 diabetes using patient self-report: the diabetes complications index. J Ambul Care Manage 2005;28:262-73.

36 Fujita E, Kuno E, Kato D. Development and validation of the Japanese version of the patient activation measure 13 for mental health. Seishin Igaku 2010;52:765-72.

37 Hibbard JH, Mahoney ER, Stock R, et al. Do increases in patient activation result in improved self-management behaviors? Health Serv Res 2007;42:1443-63.

38 Kato A, Fujimaki Y, Fujimori S, et al. Data from: how self-stigma affects patient activation in persons with type 2 diabetes. Dryad Digital Repository 2020.

39 Scheff TJ. Being mentally ill: a sociology theory. Chicago: Aldine, 1966.

40 Kato A, Yoshiuchi K, Fujimaki Y, et al. Understanding the experiences of long-term maintenance of self-worth in persons with type 2 diabetes in Japan: a qualitative study. BMJ Open 2020;10:e034758 